$1-1-1981$

\title{
Physicians and Lawyers: Science, Art, and Conflict
}

Robert L. Schwartz

University of New Mexico - School of Law

Joan M. Gibson

Follow this and additional works at: https://digitalrepository.unm.edu/law_facultyscholarship

Part of the Health Law and Policy Commons

\section{Recommended Citation}

Robert L. Schwartz \& Joan M. Gibson, Physicians and Lawyers: Science, Art, and Conflict, 6 American Journal of Law \& Medicine 173 (1981).

Available at: https://digitalrepository.unm.edu/law_facultyscholarship/12

This Article is brought to you for free and open access by the UNM School of Law at UNM Digital Repository. It has been accepted for inclusion in Faculty Scholarship by an authorized administrator of UNM Digital Repository. For more information, please contact amywinter@unm.edu, Isloane@salud.unm.edu,sarahrk@unm.edu.

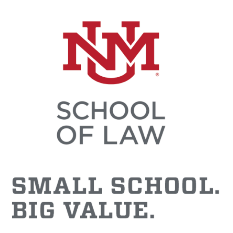

BIG VALUE. 


\title{
Physicians and Lawyers: Science, Art, and Conflict
}

Joan M. Gibson, Ph.D.*

Robert L. Schwartz, J.D.**

\begin{abstract}
The relations between physicians and lawyers have deteriorated rapidly over the past several decades, most particularly since the early 70 s when the perception that a medical malpractice crisis existed in America became widespread. Some believe that the factors dividing the two professions are linked (1) to professional jealousy, (2) to sometimes conflicting economic interests, or (3) to difficulties in communication, since both professions use many of the same words, or terms of art, but with different intended meanings.

While the authors agree that these factors may have aggravated the problem, they believe that the conflict's real roots are in the very different ways in which physicians and lawyers are trained and in the different epistemologies that each profession has accepted, as a result of which each reasons and solves problems in a manner that not only diverges from but sometimes contradicts the other's. The authors conclude that only as the varying epistemologies begin to converge can physicians and lawyers begin to approach problems in more similar ways, and to discover the underlying compatibility of many of their interests and goals.
\end{abstract}

\section{THE PROBLEM}

Over the past several decades, relations between physicians and lawyers have undergone considerable change. Once based on mutual respect and even trust, the two professions' attitudes towards one another have deteriorated into mutual hostility and mistrust. With the advent in the early 1970s of what was widely perceived to be a medical malpractice insurance crisis, the divisions between them deepened, and have, if anything, grown more formidable since then.

In recent years, there has been a slight shift in attitude, as a dialogue has begun-at universities and through a few professional organizations ${ }^{1}$ -

* Associate Professor of Philosophy and Bioethics, University of Albuquerque, Albuquerque, New Mexico.

* Associate Professor of Law, University of New Mexico, Albuquerque, New Mexico.

1 See Wecht, The Interfaces of Law and Medicine (American Society of Law and 
between the two professions. This incipient dialogue has not, however, extended to communications between most practicing physicians and lawyers. At best, it has usually been limited to exchanges between lawyers and the handful of enrolled physicians whom they are teaching about substantive law, and to exchange between physicians and the handful of enrolled lawyers whom they are teaching about particular illnesses and injuries, with no significant effort being made by either group, even during these exchanges, to understand the other's reasoning process. At the same time, the increase in the number and severity of successful malpractice actions brought against physicians ${ }^{2}$ - what, they term the malpractice crisis ${ }^{3}$-has considerably increased the antagonism between the two professions.

Simultaneous with the observed loss of respect of physicians and lawyers for each other, both professions-though surely the most respected in the English-speaking world for the past two centuries-have been losing the esteem they once had in the community. The time when both physicians and lawyers were considered "men of mystery and magic, members of a sacerdotal class in close communion with God,"4 has passed. Just as the public's perception of physicians as having unique powers to work mysterious cures has lapsed, so the powerful respect for the rule of law as formal authority has increasingly been questioned.

\section{SUGGESTED EXPLANATIONS}

Undoubtedly, the decline in respect accorded both professions by the community has contributed to the defensiveness of each professional group, and to the tendency of each to denigrate the apparent self-righteousness of the other. In addition, some believe that this defensiveness is reinforced by the potentially competing economic interests of the two professions. Clearly, physicians feel attacked economically as well as professionally by the increased prosecution of medical malpractice actions. Arguing that the threat

\footnotetext{
Medicine 1974 Annual Oration), 1 AM. J. L. \& MED. 89 (1975). The American Society of Law and Medicine is one of the important national organizations dedicated to the development of such a dialogue. The dialogue is also heard at meetings of state bar associations (most of which now have medicine and law committees) and state medical associations (many of which have sections on legal medicine), and at medical-legal liaison committees (often joint ventures of the state legal and medical societies). Other institutions, such as the Hastings Center, Institute of Society, Ethics, and the Life Sciences, have been successful in bringing lawyers and physicians together with other professionals.

2 J. Kinc, The Law of Medical Malpractice 922.24 (1977); see also Abraham, Medical Malpractice Reform: A Preliminary Analysis, 36 MD. L. REv. 489, 490 n.3 (1977).

3 See, e.g., Rubsamen, Medical Malpractice, Scientific AM., Aug. 1976, at 18-23; see also Malpractice Nightmare. TIME, Mar. 24, 1975, at 62-63. The courts too have recognized the "alleged 'medical malpractice insurance crisis'," Jones v. State Bd. of Medicine, 97 Idaho 59, 555 P.2d 399, cert. denied, 431 U.S. 914 (1977), and every state legislature has promulgated some statute to deal with it. See White \& McKenna, Constitulionality of Recent Malpractice Legislation, 12 ForUM 312 (1977).

4 M. Guttmacher \& H. Weihofen, Psychiatry and the Law 3 (3d ed. 1952).
} 
of such litigation could make the practice of medicine financially impossible, physicians have been strong supporters of legislation limiting the kinds of medical malpractice actions available, the time during which they may be pursued, and the amount of recovery available to the plaintiff. Not surprisingly, lawyers view these statutes, together with attempts to limit the use of contingent fee arrangements in medical malpractice cases, ${ }^{5}$ as an economic threat as well as a challenge to their legal and legislative expertise. Nevertheless, malpractice litigation has apparently not had any perceptible effect upon physicians' incomes, and malpractice legislation has not had a substantial impact upon lawyers' incomes. ${ }^{6}$ Thus, it appears that other considerations must play a role in the breakdown of relations between the two professions.

A third suggested explanation for the difficulty physicians and lawyers now have in communicating is the extent to which they intentionally attach different meanings to the same words. The words need not be part of medical or legal jargon for this problem to arise. One obvious example is the different medical and legal definitions and interpretations given the word "causation":?

The legal approach to causation differs markedly from the medical approach to which the physician is accustomed through his specialized training and experience. For example, in viewing a patient's current medical problems, physicians more or less instinctively search for the basic cause or causes of the disorder that underlies those problems. Judges and attorneys, in contrast, seek to determine whether one particular event precipitated, hastened, or aggravated the patient's current condition. Furthermore, physicians, oriented toward treating the entire patient, strive to identify and to understand all aspects of the patient's condition, whereas judges and attorneys tend to limit their concern to only that aspect of the patient's condition that allegedly was precipitated, hastened, or aggravated by the event in question. ${ }^{8}$

5 See, e.g., Ind. Code ANN. \$ 16-9.5-5-1 (Burns Cum. Supp. 1979) (limiting contingent fees in medical malpractice actions to $15 \%$ ). The contingent fee was the subject of specific consideration in the Department of Health, Education, and Welfare, Report of the Secretary's Commission on Medical Malpractice 34 (1974).

6 Physicians remain the best paid professionals in the country, and lawyers rank close behind. In 1976, self-employed physicians had an average annual income of $\$ 62,799$, roughly four times the annual average income for the profession in 1955 . INformation Please Almanac 87 (1979) (citing Council on Wage and Price Stability). For a comparison of lawyers' pay with that of other professionals, see National Survey of Professional, Administrative, Technical, and Clerical Pay, Bureau of Labor Statistics Bulletin 2004 (1978).

7 The differing legal and medical definitions of that word are demonstrated in a dozen articles written on the subject. Danner \& Sagall, Medicolegal Causation: $A$ Source of Professional Misunderstanding, 3 AM. J.L. \& MED. 303 n.l (1977).

8 Id. at 304. 
Similar problems arise with a number of other words-such as "illness," "injury," and "harm"- some of which have become separate terms of art in each profession. Although these semantic differences may be frustrating, they do not exemplify an essential philosophical difference, or even a substantive difference in the notion of what ought to give rise to liability. Thus, the differences in terminology, either alone or in tandem with the theories explored above, do not explain the profound levels of suspicion and hostility that divide the two professions.

\section{THE UNDERLYING EXIPLANATION}

The authors contend that the most significant explanation for this deep-seated antagonism between the two professions is that physicians and lawyers do not reason and solve problems in the same way. At first glance it would seem unlikely that these two professions would reason in radically different ways. Prospective physicians and lawyers tend to come from the same social classes and to have the same kinds of backgrouncls: they grow up in the same suburbs, go to the same secondary schools, and attend the same colleges. Indeed, it would be difficult to find two groups who ought to think as much alike as physicians and lawyers. If they reason in different ways, then, the explanation must lie in the nature of the professions themselves, or in the nature of the education that socializes law and medical students into their respective professions.

Indeed, the ways in which physicians and lawyers analyze problemsfor example, the ways in which they invoke the scientific method-are very different; in fact, the two professions look for truth in unrelated ways. While medicine seeks objective, absolute truths; the law, employing the adversary system, seeks relative truths. The adversary system requires that every idea and argument be tested, and that only those that remain aiter being assailed be accepted as the relatively better truth. In theory, therefore, a court makes a finding by having an able advocate present the best arguments on one side of an issue and then having another equally able adrocate present the arguments supporting a contrasting conclusion. Out of this battle of ideas, the legal system supposes, the strongest-or stronger-argument will emerge victorious. This system of discovering truth necessarily admits that there is no single and clearly superior truth in any particular case. The question is not which argument is right and which is wrong, but which argument is the better one.

The law student learns this method of determining truth from the first day of law school. Although some law schools have begun to change their teaching methods, most still employ the Socratic method almost exclusively during the first semester, if not longer." Basically a discussion and argument

9 The large-class, case method of instruction, usually in a Socratic question and answer format, has dominated law teaching since it was pioneered nearly a cen. 
method of teaching, it is intended to demonstrate the law's first assumption -that the best argument will prevail only if every argument, and every position, is challenged.

The notion of the adversary system is largely inconsistent with the way in which physicians make decisions. Despite some powerful dissent from this view, most physicians consider medicine to be more of a science than an art. Diagnoses are developed not through debate or through the challenge of ideas, but through dispassionate research and careful as well as neutral evaluation of a set of natural facts. It was seventy years ago that Alexander Flexner, commissioned to evaluate medical teaching in the United States, pointed out that "in methods of instruction... out and out didactic treatment is hopelessly antiquated; it belongs to an age of accepted dogma or supposedly complete information, when the professor 'knew' and the students 'learned'."10

Although the role of clinical medical education has expanded since that time, the notion that the professor-in the classroom or on the ward — "knows" and that the students "learn" has scarcely changed. ${ }^{11}$ Whereas law students are pushed to answer examinations with the strongest answers, medical students are asked to provide the right answers.

Are the differences in the ways in which physicians and lawyers think, reason, and argue simply the perpetuation of different teaching methods and professional traditions imposed during, and continued after, law and medical school? While these differences are reflected in the respective educational systems, they appear to go beyond methodology. Rather, they seem to be linked to the content and structure of medical "science" and law, and to the implicit theories of reality that accompany each.

Science, as an activity involving both discovery and explanation of natural phenomena, is generally understood to comprise procedures of observation, identification, description, experimental investigation, and theoretical explanation. Law, on the other hand-at least since the advent of legal realism ${ }^{12}$-has been defined as constituting the development (and

tury ago. The reasons for the longevity and popularity of the case method are several: its general pedagogical effectiveness, particularly in comparison to lecturing; its adaptability to large classes and thus its low cost; and, perhaps most important, its ability to accommodate differing intellectual currents and differing conceptions of law.

Boyer \& Crampton, American Legal Education: An Agenda for Research and Reform, 59 Cornell L. Rev. 221, 224-25 (1974) (footnotes omitted).

10 Hamilton, The McMasters Curriculum: A Critique, 1976 Brir. Med. J. 1191 (quoting

A. Flexner, Medical Education in the United States and Canada (1910)).

11 Id.

12 Legal realism, which was very influential in legal education in the 1930s, and very popular among judges of the most prestigious courts at the same time, rejected the notion that the law was a matter of objective moral truths to be discovered by judges. Instead, legal realism defined the law as that collection of beliefs, views, and prejudices that did, in fact, exist within the society, that change from time to time and from society to society, and that lawyers and judges are obliged to discover, and to form. For a general 
not just the discovery) of a system of relations for those living in a society, and as "behavioral directives about interpersonal actions." 13

Physicians-as-scientists view their functions (observation, identification, description, investigation, and explanation of natural phenomena) within the theoretical confines of their discipline. They usually accept the notion of scientific law as a formulation of observed recurrences, order, relationships, or interactions of natural phenomena. Even the theories to which they turn, while not, by definition, based directly on observable phenomena, must ultimately be validated by reference to confirmed experimental law - to observably simple and definitively true statements about the nature or behavior of natural phenomena. And while the term "law" is neither a precisely nor a comprehensively defined term for scientists, " $\mathrm{t}]$ here is . . . agreement that a minimum necessary condition of any scientific statement proposed as lawlike is that it be a universal generalization." 14 To have any meaning, scientific laws must accurately predict an event, a relationship, or a consequence, and to the extent that physicians see themselves as scientists, their reality is described and controlled by laws that must be empirically verifiable and universally generalizable.

The lawyer deals with laws of a very different sort. Legal rules can be prescriptive, as well as descriptive, and thus are not empirically verifiable in the same manner as "scientific" laws. While verification of a law is the hallmark of the scientific method, it is simply irrelevant to most legal inquiry. A scientific law is "truth" because it accurately describes an attribute of the universe, and thus applies to all societies and all times. A law announced by a common law court is "truth" because the community, authoritatively represented in this instance by a majority of the court's members, believes it works well in individual cases that have arisen. It is not, however, universally generalizable; it may, in fact, be inconsistent with laws adopted by different societies.

The distinction between the legal and medical concepts of law is especially significant because of their recent origins. Indeed, it was not until the 1930 s that " $[t]$ he realist movement (in law schools) finally killed the idea of law as an exact science. Legal rules could no longer be assumed to be value-free. Their predictive value was seriously questioned. The emphasis on legal observation was finally established as being process rather than substance."1s

Today, while physicians-as-scientists dwell largely in the realm of physis, where the laws of nature are "given" presumably independently, lawyers inhabit the world of nomos, where laws of society are "affirmed" by specific

discussion of the role of legal realism, see G. Gilmore, The Ages of American Law 77.80 (1977).

13 C. Burns, Legacies in Law and Medicine 299 (1977).

144 Encyclopedia of Phil. 411 (1972 reprint).

15 Stevens, Two Cheers for 1870: The American Law School, in LAw IN AMrRicaN History 405, 480-81 (B. Bailyn \& D. Fleming eds. 1972). 
acts of human will. The physician is concerned with human beings' relation to nature, as explained and managed according to discoverable scientific laws. The lawyer, on the other hand, is concerned with human beings' relation to one another (either singly or in groups), precisely as this involves the formulation and enactment of rules to regulate relations and transactions. Concepts such as guilt, fault, intention, responsibility, liability, obligation, duty-the substance of legal rules-simply cannot be verified or even explained by appeal to scientific law in any usual sense. Thus, the content and structure of the realities with which physicians and lawyers deal on a daily basis are strikingly dissimilar.

The implications of this reality are significant. Consider the earlier discussion of the different meanings physicians and lawyers assign to terms such as "causation," and it will appear now that these semantic differences themselves entail something more basic: physicians and lawyers work within, or create, qualitatively different sorts of "factual" contexts and intellectual environments out of which causal relations may be inferred. For example, experimental scientists, and physicians to the extent that they are trained as scientists, inquire into those general conditions that typically accompany, cause, or entail an instance of a certain kind. While this is but one of many possible notions of causal explanation, it stands in marked contrast to the legal notion of proximate cause - that cause so closely related to the undesirable end that it ought to give rise to legal liability. Whereas a physician might describe the cause of a death as cardiac arrest, a lawyer might describe the cause of the same death as a gunshot fired by a named assailant-a gunshot that triggered the particular sequence of physiological events that resulted in the victim's cardiac arrest and death. The problem is not that one description of the cause contradicts the other; they are, of course, perfectly consistent. The problem is that one has little or nothing to do with the other. As Michael Polanyi says, in discussing the necessity for presumptions in establishing appropriate contexts for inquiry:

The dogmatic and often arbitrary character of legally imposed beliefs is justified by the peculiar context in which they are established and affirmed. The court does not try to find out the truth about certain interesting events, but only to find-by a legally prescribed procedure-the facts relevant to a certain legal issue. The will to believe these affirmations, even when they are not justifiable in themselves, originates in the will to do justice by making these affirmations and acting upon them. There is therefore, strictly speaking, no possible contradiction between the factual findings of a court of law and those of scientific and ordinary experience. They by-pass each other. ${ }^{16}$

This very difference in the way physicians and lawyers think also 
creates a difference in the way they talk. To the lawyer, a single word-like "causation"-may describe several different concepts, if logic or justice, or both, require it to do so. Words are the tools lawyers use to explain underlying ideas. For physicians, however, words tend to take on substantial and unchangeable meanings that are more than merely descriptions of the universe-they are the universe. According to one medical school professor who believes that this essentialist view makes it more difficult for physicians to make a truly scientific inquiry:

Much bad practice and equivocal research stems from a belief that an "essence" lies behind medical terms. I suspect this is a heritage from the primitive need to believe in external agents, spirits, [or] humours as a way of explaining illness; a belief kept going by the discovery of germs. Such a belief may account for the discomfort [physicians] evince when faced with the choice of calling some condition a "syndrome" or a "disease."

These matters may seem intellectual and arid, Attempts to discuss them always irritate medical audiences, who regard them as semantic (this adjective having acquired a pejorative taint) . . ..$^{17}$

This difference in the professions' approaches to language is much more than a semantic difference in the way certain terms are used. It is a con. sequence of the fact that physicians and lawyers have chosen very different means to define truth, and, ultimately, that both are searching for different truths, unrelated to one another.

On the other hand, physicians' concept of truth, based on a scientific model that underlies their training, does not encompass the fact that what they actually do in the practice of medicine is at least as much art as it is science, that is, it incorporates relative as well as absolute truths. After all, "[m]edicine as medicine comes most fully into existence in [acts] of clinical decision-making." 18 Such acts demand the making of a choice "among the many things that can be done, of those things which should be done for a particular patient. Medicine seeks a right healing action, one which works for a particular patient as he or she presents himself or herself in a particular clinical moment and life situation." 19 Seen in this perspective, the physician, like the lawyer, is involved in prescriptive and value-laden acts of decision making. If, as this analysis suggests, the "end of medicine, its justifying principle, is, in the final analysis, a moral one, dealing with . . . questions of value, morality, and interpersonal dynamics," 20 how does training in the scientific method prepare the medical student to accommodate 135.

17 Campbell, Basic Science, Science, and Medical Education, 1976 The Lancet 134,

18 Pellegrino, Medicine, Science, Art: An Old Controversy Revisited, 4 L. \& MED. 44 (1979).

10 Id.

20 Id. at 47. 
this end? Until the value-laden nature of medical practice is recognized by the medical schools, it is unlikely that this question can be answered satisfactorily. ${ }^{21}$

So long as science, without art, provides the model for the medical practitioner, the different methods physicians and lawyers use to solve problems will perpetuate mistrust between the professions. A physician who is a defendant in a malpractice case may very reasonably explain to his or her lawyer that he or she is an expert in the field, knows more about the challenged procedure than anyone else, and did not err. The physician is sure to be surprised and frustrated when the lawyer informs him or her that implicit in the legal system is the belief that justice is more likely to be done if the plaintiff presents another physician, equally knowledgeable in the field and equally articulate, who believes that the defendant did err. Until physicians recognize that the adversary system and all of its attributes -including cross examination of the physician and of other experts-do not constitute a personal attack on the competency of the physician, they will mistrust the system. Similarly, until lawyers realize that a physician's training leaves no room for an adversary inquiry, they are likely to mis. understand physicians' responses to their questions.

\section{CONCLUSION}

To eradicate the existing high level of suspicion and hostility between the two noble professions of law and medicine will require more than simply training physicians in the substantive law or teaching lawyers how to use a medical library, although these steps may help each profession to understand the other in certain specific ways. For the underlying problem to be resolved, however, each one must understand the other's reasoning process.

Some small steps are being taken in legal and medical education to achieve this goal. In fact; the most interesting consequence of the quest to understand one another may be the discovery of just how much each one mimics, and respects, the other's approach. Individual law schools have reacted to the legal realist movement by attempting to base law on more clearly, and universally, adopted first principles-that is, to make law more scientific. ${ }^{22}$ This effort helps to explain the continued vitality of the Socratic

21 Indeed, there are those who believe that the century-old attempt to separate science from ethics must necessarily fail. Over the past few years the argument for the reunification of the disciplines-in one form or another-has been made very persuasively. See, e.g., Toulmin, Can Ethics and Science Be Reconnected?, 9 The Hastings Center REPORT 27 (1979).

22 Of course, these first principles may not be "scientific" in the traditional sense. For an interesting account grieving the apparent passing of religious principles and foundations as first principles of American legal study, and perhaps American law, see Berman, The Secularization of American Legal Education in the Nineteenth and Twentieth Centuries, 27 J. LeGal Eb. 382 (1975). 
teaching method, which, when it was applied to legal education a century ago, was thought to be appropriate for teaching legal "science." Conversely, medical schools have reacted to medical education's orientation toward the pure sciences by acknowledging that medicine is much more than the discovery and application of universal rules. If physicians do not yet accept Toulmin's theory that scientific methodology is, or ought to be, developed on a common law model, ${ }^{23}$ they at least recognize that what "works" for a patient is as much a product of creativity as it is a mechanical deduction from previously established scientific truths.

As each profession comes to understand the epistemology of the other, and to broaden the definition of its own, physicians and lawyers can begin to recognize the similarities in many of their interests and goals, to renew the respect that once bound them, and to cut through the many misunderstandings and conflicts that now divide them. The result would be not only smoother personal relations between them, but also the development of more effective approaches to the many challenging problems that physicians and lawyers face together.

23 Toulmin, "From Form to Function," in Studies in Contemporary Scholarship, 106 Daedalus 154 (1977). 